\title{
IGF1 for the diagnosis of growth hormone deficiency in children and adolescents: a reappraisal
}

\author{
Anastasia Ibba' ${ }^{1}$, Francesca Corrias ${ }^{2}$, Chiara Guzzetti ${ }^{1}$, Letizia Casula ${ }^{1}$, Mariacarolina Salerno ${ }^{3}$, Natascia di lorgi ${ }^{4,5}$, \\ Gianluca Tornese ${ }^{2}$, Giuseppa Patti ${ }^{4,5}$, Giorgio Radetti ${ }^{6}$, Mohamad Maghnie ${ }^{4,5}$, Marco Cappa ${ }^{7}$ and Sandro Loche ${ }^{1}$ \\ ${ }^{1}$ SSD Endocrinologia Pediatrica e Centro Screening Neonatale, Ospedale Pediatrico Microcitemico 'A. Cao', AO Brotzu, Cagliari, Italy \\ ${ }^{2}$ SSD Endocrinologia Pediatrica, Clinica Pediatrica, IRCCS Materno-infantile Burlo Garofolo, Trieste, Italy \\ ${ }^{3}$ Dipartimento di Pediatria, Università Federico II, Napoli, Italy \\ ${ }^{4}$ Dipartimento di Pediatria, IRCCS Istituto Giannina Gaslini, Università di Genova, Genova, Italy \\ ${ }^{5}$ Dipartimento di Neuroscienze, Riabilitazione, Oftalmologia, Genetica e Scienze Materno-infantili, Università di Genova, Genova, Italy \\ ${ }^{6}$ Dipartimento di Pediatria, Ospedale Generale Regionale, Bolzano, Italy \\ 7UOC di Endocrinologia, Dipartimento Universitario Ospedaliero, Ospedale Pediatrico Bambino Gesù IRCCS, Roma, Italy
}

\begin{abstract}
A number of studies have evaluated the role of IGF1 measurement in the diagnosis of growth hormone deficiency (GHD). This study aimed to evaluate the accuracy and the best cut-off of IGF1 SDS in the diagnosis of GHD in a large cohort of short children and adolescents. One-hundred and forty-two children and adolescents with GHD ((63 organic/ genetic (OGHD), 79 idiopathic (IGHD)) and 658 short non-GHD children (median age 10.4 years) were included in the analysis. The two groups were subdivided according to age ( $G 1<6, G 26<9, G 39<12, G 4 \geq 12$ ) and to pubertal status. Serum IGFI was measured by the same chemiluminescence assay in all samples and expressed as age- and sex-based SDS. Receiver operating characteristic (ROC) analysis was used to evaluate the optimal IGF1 SDS cut-off and the diagnostic accuracy. Median IGF1 SDS was significantly lower in the GHD than in non-GHD patients. The area under the curve (AUC) was 0.69 , with the best IGF1 cut-off of -1.5 SDS (sensitivity $67.61 \%$, specificity $62.62 \%$ ). The AUC was 0.75 for OGHD and 0.63 for IGHD. The accuracy was better in the pubertal $(A \cup C=0.81$ ) than the prepubertal group (AUC $=0.64$ ). In our cohort, IGF1 measurement has poor accuracy in discriminating GHD from non-GHD. Our findings confirm and reinforce the belief that IGF1 values should not be used alone in the diagnosis of GHD but should be interpreted in combination with other clinical and biochemical parameters.
\end{abstract}

\author{
Key Words \\ - growth hormone \\ deficiency \\ - insulin-like growth factor 1 \\ - children \\ - adolescents \\ - short stature
}

\section{Introduction}

The diagnosis of growth hormone deficiency (GHD) in childhood and adolescence is based on auxological, biochemical, neuro-radiological, and genetic investigations. Since GH production is pulsatile, its secretion needs to be assessed by provocative tests. A number of different $\mathrm{GH}$ secretagogues and testing modalities have been proposed over the last decades $(1,2)$. However, their interpretation remains problematic for many reasons $(3,4)$. Pharmacological stimuli are not physiological, the diagnostic cut-off is often arbitrarily established, testing modalities and GH assays are widely variable among different centres. Furthermore, GH secretion may be influenced by factors such obesity, undernutrition, sex, age and puberty $(4,5)$. Finally, provocative tests are time-consuming, costly and entail discomfort for the patients. 
The decision to perform a GH stimulation test should be based on the severity of short stature, height velocity, medical history and physical examination findings. The diagnostic cut-off for the stimulated GH peak was initially set at $5-7 \mu \mathrm{g} / \mathrm{L}$, subsequently was arbitrarily increased to $10 \mu \mathrm{g} / \mathrm{L}(6,7,8,9,10,11,12)$. In the most recent guidelines (1) it has been set at $7 \mu \mathrm{g} / \mathrm{L}$. We have also shown that the best GH peak cut-off ranges from 5.1 to $6.8 \mu \mathrm{g} / \mathrm{L}$, depending on the stimulation test (13).

Measurement of IGF1 is also an important step in the diagnostic process $(10,14)$. IGF1 is a small polypeptide hormone, whose synthesis in the liver is stimulated by GH. IGF1 circulates primarily bound to the acid-labile subunit (ALS) and the insulin growth factor binding protein-3 (IGFBP3) $(4,5,15)$. IGF1 and IGFBP3 serum levels show little circadian variation, so that a single measurement is more reliable than a single basal GH value. However, IGF1 and IGFBP3 levels are also influenced by the type of assay (16), the patients' nutritional status, the presence of chronic illness or organ failure $(4,5,16)$, and vary with age and pubertal status. A number of studies have investigated the role of IGF1 in the diagnosis of GHD during the past decades $(1,4,14,15,17,18,19,20,21,22)$ but the results are often not comparable $(14,17)$. Overall, these studies show that IGF1 measurement has a good specificity (around 90\%) and low sensitivity (around 70\%), indicating that IGF1 levels below the reference range $(<-2$ SDS) are highly predictive of GHD but that levels within the reference range do not exclude GHD.

In the current retrospective study we aimed to define the best IGF1 SDS diagnostic cut-off using a standardized assay in a large cohort of children and adolescents with short stature. Furthermore, we wanted to evaluate through receiver operating characteristic (ROC) curve analysis (23) the accuracy of a single IGF1 measurement in the diagnosis of GHD.

\section{Subjects}

Data from 847 children and adolescents followed in six Italian Paediatric Endocrine Units (Bolzano, Cagliari, Genova, Napoli, Roma, Trieste) for short stature and/or growth deceleration between 2005 and 2019 were reviewed in this retrospective analysis. Written consent has been obtained from each subject after full explanation of the purpose and nature of all procedures used. The study was approved by the Independent Ethical Committee of the University Hospital of Cagliari (PG/2019/8866). Forty-seven patients were excluded because they were affected by an additional pathology or for incomplete data. All 800 subjects included in the study (476 boys, 324 girls, median age 10.4 years (7.07-12.70) Tanner 1-5) underwent diagnostic procedures to evaluate a possible GHD. The entire cohort was divided into two groups of GHD and non-GHD subjects. GHD was diagnosed in 142 patients with a GH peak response $<7 \mu \mathrm{g} / \mathrm{L}$ after two provocative tests. This group was then divided into two groups according to the etiology of GHD, organic/genetic GHD (OGHD, medulloblastoma $(n=3)$, germinoma $(n=9)$, craniopharyngioma $(n=19)$, astrocytic tumors $(n=5)$, ectopic posterior pituitary and/or empty sella and/or pituitary ipoplasia $(n=26)$, genetic $(n=1))$ and idiopathic GHD (IGHD).

The 658 subjects with a GH peak $\geq 7 \mu \mathrm{g} / \mathrm{L}$ and no other recognizable endocrine cause for the short stature were considered non-GHD and served as controls. Then, the GHD and non-GHD groups were subdivided into four groups according to age (G1 <6, G2 $6<9$, G3 $9<12$, G4 $\geq 12$ ). In order to analyse the influence of puberty on IGF1, the entire cohort was also subdivided into two groups according to the Tanner stage (prepubertal/Tanner 1 and pubertal/Tanner 2-5) and analysed separately comparing prepubertal $(n=102)$ vs pubertal $(n=40)$ GHD children and prepubertal $(n=527)$ vs pubertal $(n=128)$ non-GHD children. The main auxological characteristics of the subjects are summarized in Table 1 .

\section{Methods}

Clonidine and arginine stimulation tests and insulin tolerance test (ITT) were randomly used to evaluate GH reserve. According to our previous findings (13), a cutoff of $7 \mu \mathrm{g} / \mathrm{L}$ was adopted as the lowest limit for the GH peak. All children with $\mathrm{GH}$ peak $<7 \mu \mathrm{g} / \mathrm{L}$ after the first test underwent a second stimulation test on a separate day (at least 2 days apart). All the tests were performed in the morning (08:00-09:00 $\mathrm{h}$ ) after overnight fasting as previously described (13). Steroid priming was never used. Brain MRI was performed in all children with GHD. IGF1 was determined at baseline in all subjects at the moment of first testing.

\section{Assay}

Serum IGF1 and GH were measured in all subjects by chemiluminescent immunometric assay (CLIA) (Immulite 2000; Diagnostic Products Corp., Los Angeles, CA, USA). IGF1 assay was calibrated against the WHO IRR 87/518. GH assay was calibrated against the recommended IS 98/574.

This work is licensed under a Creative Commons Attribution-NonCommercial-NoDerivatives 4.0 Internationab ficense.ifica.com at 04/26/2023 02:44:50AM 
Table 1 Main clinical and laboratory characteristics of the cohort studied.

\begin{tabular}{|c|c|c|}
\hline & Total & GHD \\
\hline Subjects (n) & 800 & 142 \\
\hline Age (years) & 10.4 (7.1 to 12.7$)$ & 10.9 (8.1 to 12.7$)$ \\
\hline $\mathrm{M} / \mathrm{F}$ & $476 / 324$ & $77 / 65$ \\
\hline Height SDS & $-2.47(-2.84$ to 2.0$)$ & $-2.3(-1.77$ to 2.9$)$ \\
\hline BMI SDS & $-0.75(-1.53$ to 0.06$)$ & $0.08(-0.9$ to 0.96$)$ \\
\hline IGF1 $\mu \mathrm{g} / \mathrm{L}$ & 133.5 (83 to 196$)$ & 106 (59.7 to 147$)$ \\
\hline IGF1 SDS & $-1.27(-2.07$ to 0.41$)$ & $-1.97(-2.77$ to 1.15$)$ \\
\hline Prepubertal (n) & 592 & 102 \\
\hline Pubertal (n) & 110 & 40 \\
\hline
\end{tabular}

\begin{tabular}{c}
\hline Non-GHD \\
\hline 658 \\
$10.3(6.8$ to 12.7$)$ \\
$399 / 259$ \\
$-2.5(-2.8$ to 2.05$)$ \\
$-0.89(-1.64$ to 0.18$)$ \\
$140.5(90.25$ to 207.8$)$ \\
$-1.13(-2.0$ to 0.29$)$ \\
490 \\
70
\end{tabular}

\begin{tabular}{c}
\hline P-value \\
\hline 0.1149 \\
0.0222 \\
$<0.0001$ \\
$<0.0001$ \\
\hline
\end{tabular}

\begin{tabular}{c}
\hline OGHD \\
\hline 63 \\
$11.2(7.85$ to 13.02$)$ \\
$36 / 27$ \\
$-2.2(-2.9$ to 1.4$)$ \\
$0.33(-0.37$ to 1.0$)$ \\
$74.05(41.4$ to 136.5$)$ \\
$-2.26(-3.59$ to 1.48$)$ \\
38 \\
25 \\
\hline
\end{tabular}

\begin{tabular}{c}
\hline IGHD \\
\hline 79 \\
$10.85(8.0$ to 13.0$)$ \\
$41 / 38$ \\
$-2.35(-2.9$ to 1.9$)$ \\
$-0.06(-1.33$ to 0.9$)$ \\
$119.5(84.63$ to 160.5$)$ \\
$-1.84(-2.3$ to 0.8$)$ \\
64 \\
15 \\
\hline
\end{tabular}

All values are reported as median and interquartile range (IQR).

GHD, growth hormone deficiency; IGHD, idiopathic growth hormone deficiency; IGF1, insulin-like growth factor 1; OGHD, organic/genetic growth hormone deficiency; SDS, standard deviation score.

The sensitivity of the method was $2.6 \mathrm{nmol} / \mathrm{L}$ for IGF1 and $0.01 \mu \mathrm{g} / \mathrm{L}$ for $\mathrm{GH}$. The IGF1 intra- and inter-assay coefficients of variation were 3.4 and $7.1 \%$, respectively. The GH intra- and inter-assay coefficients of variation were, respectively, $4.2-6.6$ and $2.9-4.6 \%$ at GH levels of $2.6-17 \mu \mathrm{g} / \mathrm{L}$. Consistency of assay performance was assessed by regular use of internal controls.

\section{Statistical analysis}

Age and sex-based IGF1 SDS values were calculated using the normative data for the method (24) according to the following formula: IGF1 SDS (Z-score) $=(\log$ IGF1 $\mathrm{ng} / \mathrm{L}$ - log mean for age and sex)/log mean s.D. Height SDS and BMI SDS were derived from the Italian reference data (25). Height velocity SDS was derived from Tanner's charts (26).

Kolmogorov-Smirnov test was used to evaluate the distribution of the data. Comparison between groups was performed using the Student's t-test and the MannWhitney U-test for normally distributed variables and for not-normally distributed variables, respectively. ROC analysis (23) was used to evaluate the optimal IGF1 SDS cut-off (best pair sensitivity and specificity values) and the diagnostic accuracy of IGF1 for all the groups considered. The best pair sensitivity and specificity values were calculated according to the Youden index. The area under the curve (AUC) was used to measure the accuracy of the test and was considered with 95\% CI. Likelihood ratios for a positive test result ( $\mathrm{LR}+$ ), and the efficiency (Ef, the number of correct results divided by the total number of tests) were provided as a measure of diagnostic accuracy. All values were reported as median and interquartile range (IQR) (continuous variables) or as counts and percentages (categorical variables). Sensitivity, specificity, positive and negative predictive values (PPV and NPV) were expressed as percentage. $P<0.05$ (two sided) was considered significant. All statistical calculations were performed using GraphPad Prism version 8.4 software, Inc.

\section{Results}

The clinical and biochemical characteristics of the subjects are summarized in Table 1. Height SDS was similar in the two groups, while, as expected, BMI SDS was higher in the GHD group. The median IGF1 SDS was $-1.97(-2.77$ to 1.15$)$ and -1.13 (-2.0 to 0.29$)$ in GHD and non-GHD subjects, respectively (Table 1$)$. The median IGF1 SDS was similar between prepubertal GHD $(-1.94,-2.56$ to 0.92$)$ and pubertal GHD $(-2.02,-3.32$ to 1.43$)$, while it was significantly higher in pubertal $(-0.73,-1.56$ to 0.16$)$ than in prepubertal non-GHD (-1.0, -1.9 to 0.2$)$ (Table 2). IGF1 SDS was significantly lower in prepubertal GHD $(-1.94,-2.56$ to 0.92$)$ and pubertal GHD $(-2.02,-3.3$ to 1.4) than in prepubertal non-GHD $(-1.2,-2$ to 0.4$)$ and pubertal non-GHD $(-0.73,-1.56$ to 0.16$)$, respectively (Table 2).

\section{ROC curve analyses}

The results of the ROC analyses are reported in Figs 1, 2, 3 and Tables 3, 4, 5 .

The AUC (measure of discriminative ability of the test) for IGF1 SDS was 0.69 (95\% CI: 0.64-0.74). The best pair of values for Se and Sp (67.61 and 62.62\%, respectively) was found at the cut-off of -1.5 SDS (LR+ 1.80, efficiency: 67.6\%, PPV: 28.07\%, NPV: $89.95 \%)$. Thus, using the IGF1 SDS cut-off -1.5 a correct diagnosis was possible in 96 GHD patients $(67.6 \%(n=47$ OGHD, $n=49$ IGHD)) and 412 non-GHD subjects (62.61\%). At the IGF1 cut off of -2 SDS, Sp and Se were 46.4 and $77.2 \%$, respectively, with a LR+ of 2 and Ef of $63 \%$, PPV $30 \%$, NPV $86 \%$. 
Table 2 Differences between groups according to pubertal status.

\begin{tabular}{|c|c|c|c|}
\hline IGF1 SDS & Prepubertal & Pubertal & P-value \\
\hline GHD (n) & $\begin{array}{l}102 \\
-1.94(-2.56 \text { to } 0.92)\end{array}$ & $\begin{array}{l}40 \\
-2.02(-3.32 \text { to } 1.43)\end{array}$ & 0.114 \\
\hline Non-GHD (n) & $\begin{array}{l}527 \\
-1.2(-2 \text { to } 0.4)\end{array}$ & $\begin{array}{l}128 \\
-0.73(-1.56 \text { to } 0.16)\end{array}$ & 0.001 \\
\hline$P$-value & $<0.0001$ & $<0.0001$ & \\
\hline
\end{tabular}

All values are reported as median and interquartile range (IQR). GHD, growth hormone deficiency; IGF1, insulin-like growth factor 1; SDS, standard deviation score.

The AUC for OGHD IGF1 SDS was 0.75 (95\%CI: 0.69-0.82) with IGF1 SDS best cut-off of -1.71 (Se: $74.6 \%$ and Sp: 67.33\%; LR+ 2.28, Ef: 66\%, PPV: 18.3\%, NPV: 95.06\%). The AUC for IGHD IGF1 SDS was 0.63 , best cutoff was -1.51 SDS (Se: $62.03 \%$, Sp: $62.92 \%$, LR+ 1.67, Ef: 62.02\%, PPV: 16.2\%, NPV: 93.04\%). The ROC analyses for the non-GHD and OGHD groups ROC yielded an AUC of 0.75 (95\% CI: 0.69-0.82). The best IGF1 SDS cut-off to discriminate between non-GHD and OGHD groups was -1.71 (Se: 74.6\% and Sp: 67.33\%; LR+ 2.28, Ef: 67.4\%, PPV: 17.66\%, NPV: 96.48\%). The results of ROC analyses according to age groups and pubertal status are reported in Figs 2, 3 and Tables 4, 5.

\section{Discussion}

The aim of our study was to investigate the predictive value of a single IGF1 measurement in the diagnosis of GHD in a large and well-selected cohort of children and adolescents with short stature using the same IGF1 assay.

Since 1982, IGF1 measurement has been proposed as an alternative to $\mathrm{GH}$ stimulation testing for assessing GH status in short children because it is easier to perform and more reproducible (27). The usefulness of IGF1 measurement, alone or in combination with IGFBP3,

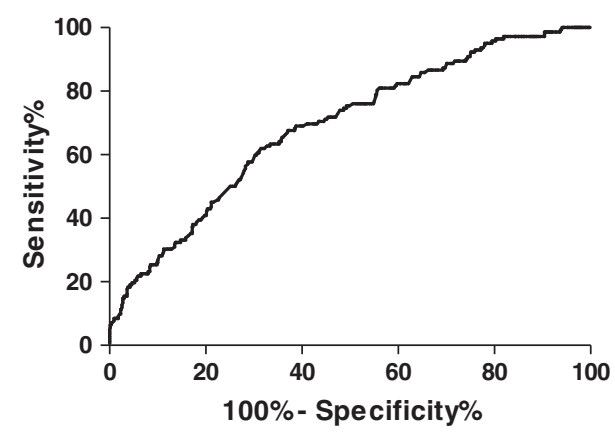

Figure 1

ROC curve for IGF1 SDS. for the diagnosis of GHD has been the subject of a number of studies $(2,4,14,17,19,28,29,30,31,32$, $33,34,35,36)$. The results of all these studies have been controversial and their findings are hardly comparable because of the use of different assays, different unit of measure (mass units, percentiles, SDS), as well as differences in patients' selection (17).

As expected, in our cohort the IGF1 SDS values were lower in GHD than in non-GHD $(19,28)$. However, our results also confirmed that IGF1 measurement alone is not reliable for the diagnosis of GHD in the single patient. We found that IGF1 measurement had poor accuracy as demonstrated by an AUC of 0.68 , and poor sensitivity, specificity and efficiency (67.61, 62.62 and 67.6\%, respectively) for the best cut-off of -1.5 SDS. The accuracy was slightly better in patients with OGHD. When we considered the IGF1 cut off of -2 SDS as recommended by current guidelines (11), we found a slight increase in specificity (77.2\%) but a marked decrease in sensitivity (46.8\%). Our findings are in contrast with the results of other authors. Ali et al. (37) and Granada et al. (38) reported high specificity and sensitivity for IGF1 and concluded that IGF1 measurement was very useful for screening patients with short stature and suspected GHD. A recent meta-analysis (17) reviewed studies that used RIA or immunoradiometric assays (IRMA) and reported an AUC for IGF1 SDS of 0.78, higher than in the present study, but still suboptimal. Both sensitivity and specificity were highly variable, ranging between 32 and 100\% (17), probably because of large differences between studies. Felìcio et al. (31) using ROC curve analysis and the same assay used in our study found similar specificity, sensitivity and accuracy in 115 subjects but at a much higher IGF1 cut-off $(-0.49$ SDS). The choice of the cut-off is one of the most controversial aspects, and in most studies it varies between -1.5 and -2 SDS (39). We found that the best cut-off to discriminate GHD patients from non-GHD subjects was -1.5 SDS. Cianfarani et al. (34) evaluated 33 GHD and 56 subjects with idiopathic short stature (nonGHD) and found that the IGF1 SDS cut-off of -1.9 best discriminated GHD from idiopathic short stature, with 73\% sensitivity and 95\% specificity. Boquete et al. (29) studied 67 subjects and found that -1.65 SDS was the best IGF1 cut-off to discriminate GHD from idiopathic short stature with sensitivity and specificity of 68 and 97\%, respectively. Binder et al. (32) proposed reference range for IGF1 SDS with the purpose to screen short children for GHD. They considered -1.4 SDS as the best cut off with $100 \%$ of sensitivity, but poor specificity $(33.3 \%)$. Furthermore, using ROC analysis they found an AUC of

This work is licensed under a Creative Commons Attribution-NonCommercial-NoDerivatives 4.0 elnternationab ficense.ifica com at 04/26/2023 02:44:50AM 
G1

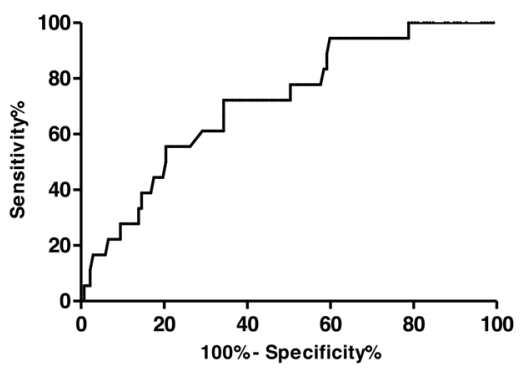

G3

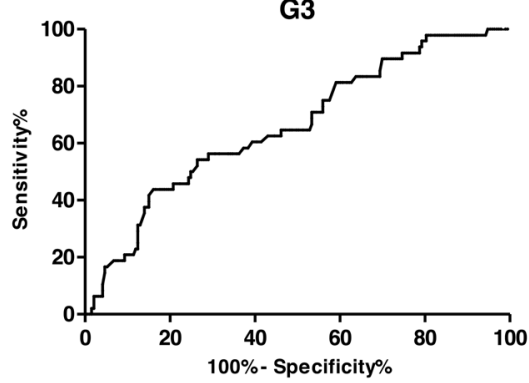

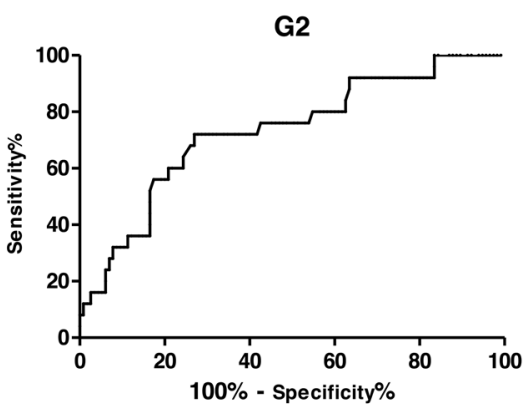

G4

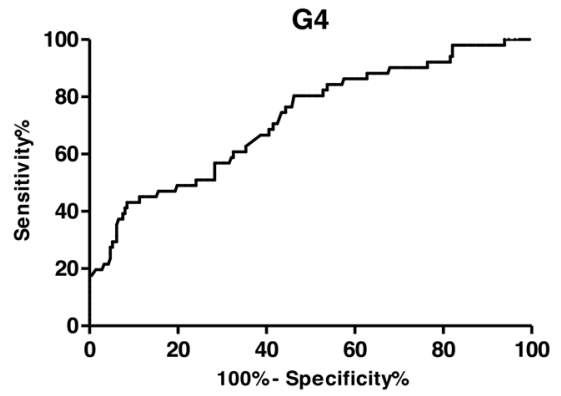

Figure 2

ROC curves for IGF1 SDS according to age.
0.8 for IGF1 SDS. In contrast we found a lower AUC with a specificity twice as high for a similar cut-off of -1.5 SDS.

Despite the high specificity, most authors concluded that IGF1 measurement is useful in the diagnosis of GHD only when combined with auxological parameters and the results of GH stimulation testing $(14,18,20,29,32,34)$.
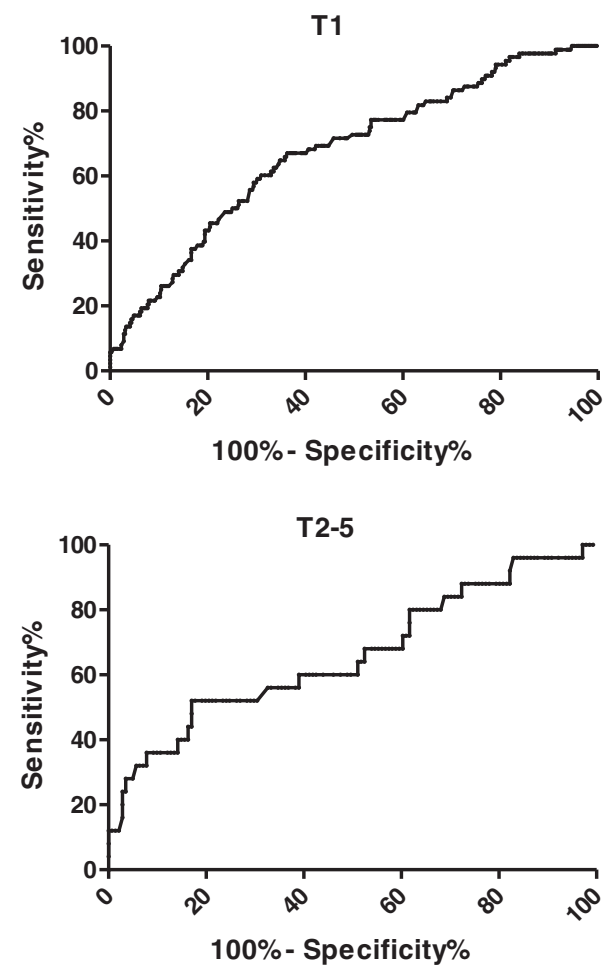

Figure 3

ROC curves for IGF1 SDS according to pubertal status.
We have previously shown that IGF1 measurement combined with $\mathrm{GH}$ provocative testing, increases the specificity of the test results, reaching $95.8 \%$ for ITT, $98.4 \%$ for clonidine test, $95.6 \%$ for arginine test, and reduces the risk of false positive results (13). In addition, our results indicate that the accuracy of IGF1 measurement is slightly better in the 6-9 years group, although sensitivity and specificity remained around 70\%. According to Cianfarani et al. (40), specificity was higher in children younger than 11, reaching $91 \%$. In our cohort we observed that specificity was higher in the $\geq 12$ years group $(91.5 \%)$ coupled with the highest diagnostic efficiency (82\%) with a best cut off of -3 SDS, but still with suboptimal accuracy $(\mathrm{AUC}=0.72)$.

Table 3 ROC curve analysis results for the entire cohort and the non-GHD vs OGHD groups.

\begin{tabular}{|c|c|c|}
\hline & \multicolumn{2}{|c|}{ IGF1 SDS } \\
\hline & GHD vs non-GHD & Non-GHD vs OGHD \\
\hline AUC & 0.69 & 0.75 \\
\hline Best cut-off (SDS) & -1.5 & -1.71 \\
\hline Sensitivity (\%) & 67.61 & 74.6 \\
\hline Specificity (\%) & 62.62 & 67.33 \\
\hline Efficiency (\%) & 67.6 & 67.4 \\
\hline $\mathrm{LR}+$ & 1.80 & 2.28 \\
\hline PPV (\%) & 28.07 & 17.66 \\
\hline NPV (\%) & 89.95 & 96.48 \\
\hline Cut-off for sensitivity at $95 \%$ & -0.13 & -0.23 \\
\hline Cut-off for specificity at $95 \%$ & -3.08 & -3.38 \\
\hline
\end{tabular}

AUC, area under the curve; GHD, growth hormone deficiency; IGF1, insulin-like growth factor 1; LR+, positive likehood ratio; NPV, negative predictive value; OGHD, organic/genetic growth hormone deficiency; PPV, positive predictive value; SDS, standard deviation score.

This work is licensed under a Creative Commons Attribution-NonCommercial-NoDerivatives 4.0 Internationab License ifica com at $04 / 26 / 2023$ 02:44:50AM 
Table 4 ROC curve analysis results for age group.

\begin{tabular}{|c|c|c|c|c|}
\hline & \multicolumn{4}{|c|}{ IGF1 SDS GHD vs non-GHD } \\
\hline & G1 & G2 & G3 & G4 \\
\hline Age (years) & $<6$ & $6-9$ & $9-12$ & $\geq 12$ \\
\hline$A \cup C$ & 0.71 & 0.73 & 0.66 & 0.72 \\
\hline Best cut-off (SDS) & -1.7 & -1.1 & -1.5 & -3 \\
\hline Sensitivity (\%) & 72.2 & 72 & 54.1 & 43.1 \\
\hline Specificity (\%) & 65.7 & 73 & 73.6 & 91.5 \\
\hline Efficiency (\%) & 65 & 71 & 68 & 82 \\
\hline $\mathrm{LR}+$ & 2.1 & 2.7 & 2 & 5 \\
\hline PPV (\%) & 21.31 & 35.29 & 32.91 & 55 \\
\hline NPV (\%) & 94.68 & 92.13 & 86.41 & 86.99 \\
\hline $\begin{array}{l}\text { Cut-off point for } \\
\text { sensitivity at 95\% }\end{array}$ & -0.35 & 0.41 & -0.03 & -0.29 \\
\hline $\begin{array}{l}\text { Cut-off point for } \\
\text { specifity at } 95 \%\end{array}$ & -3.12 & -2.48 & -2.52 & -3.48 \\
\hline
\end{tabular}

AUC, area under the curve; GHD growth hormone deficiency; IGHD, idiopathic growth hormone deficiency; IGF1, insulin-like growth factor 1; $\mathrm{LR}+$, positive likehood ratio; NPV, negative predictive value; OGHD, organic/genetic growth hormone deficiency; PPV, positive predictive value; SDS, standard deviation score.

Puberty has a profound influence on the GH-IGF1 axis. At the time of puberty, an increase in GH release follows the increased secretion of sex steroids (41). Twenty-four-hour GH concentration and, consequently, IGF1 concentrations, increase during puberty, either spontaneous, precocious or pharmacologically induced $(41,42)$. This was confirmed in our cohort, as the IGF1 concentrations rose with puberty in the non-GHD children.

We also found significant differences in IGF1 values between the OGHD and IGHD group, with best discriminative cut-off of -2.65 SDS, confirming that patients with organic and genetic GHD (i.e. usually severe GHD) have lower IGF1 values than patients with idiopathic GHD (14, 43, 44, 45, 46).

This study has the inherent limitations of all retrospective studies. Furthermore, the non-GHD group may be heterogeneous and include patients with subtle alterations of GH secretion or partial GH resistance. Likewise, some patients classified as IGHD may indeed be non-GHD subjects with falsely positive results to two stimulation tests (47). However, to our knowledge, this is the first study performed on a large well-selected population of short children and adolescents using the same IGF1 assay and a robust statistical method. In addition, the data have been obtained and analysed from the real clinical settings.

In conclusion, this study shows that the IGF1 value of -1.5 SDS is the best cut-off to discriminate between GHD and non-GHD. Slight better accuracy was observed for patients aged 6-9 years, for the organic/genetic GHD
Table 5 Roc curve analysis results for pubertal status.

\begin{tabular}{|c|c|c|}
\hline & \multicolumn{2}{|c|}{ IGF1 SDS GHD vs non-GHD } \\
\hline & Prepubertal & Pubertal \\
\hline AUC & 0.64 & 0.81 \\
\hline Best cut-off (SDS) & -1.74 & -1.5 \\
\hline Sensitivity (\%) & 58.8 & 75 \\
\hline Specificity (\%) & 66.3 & 75.7 \\
\hline Efficiency (\%) & 65 & 74 \\
\hline $\mathrm{LR}+$ & 1.75 & 3.09 \\
\hline PPV (\%) & 27 & 33 \\
\hline NPV (\%) & 88 & 96 \\
\hline Cut-off point for sensitivity at 95\% & -0.06 & -0.30 \\
\hline Cut-off point for specifity at 95\% & -3.2 & -2.75 \\
\hline
\end{tabular}

AUC, area under the curve; GHD growth hormone deficiency; IGF1, insulin-like growth factor 1; LR+, positive likehood ratio; NPV, negative predictive value; PPV, positive predictive value; SDS, standard deviation score.

group and for the pubertal group. The results of this study also confirm that IGF1 values must be interpreted in combination with other clinical and biochemical parameters for the diagnosis of GHD.

\section{Declaration of interest}

The authors declare that there is no conflict of interest that could be perceived as prejudicing the impartiality of the research reported.

\section{Funding}

This work did not receive any specific grant from any funding agency in the public, commercial or not-for-profit sector.

\section{References}

1 Collett-Solberg PF, Ambler G, Backeljauw PF, Bidlingmaier M, Biller BMK, Boguszewski MCS, Cheung PT, Choong CSY, Cohen LE, Cohen P, et al. Diagnosis, genetics, and therapy of short stature in children: a Growth Hormone Research Society International Perspective. Hormone Research in Paediatrics 201992 1-14. (https:// doi.org/10.1159/000502231)

2 Cohen P, Rogol AD, Deal CL, Saenger P, Reiter EO, Ross JL, Chernausek SD, Savage MO, Wit JM \& 2007 ISS Consensus Workshop participants. Consensus statement on the diagnosis and treatment of children with idiopathic short stature: a summary of the Growth Hormone Research Society, the Lawson Wilkins Pediatric Endocrine Society, and the European Society for Paediatric Endocrinology Workshop. Journal of Clinical Endocrinology and Metabolism 200893 4210-4217. (https://doi.org/10.1210/jc.20080509)

3 Murray PG, Dattani MT \& Clayton PE. Controversies in the diagnosis and management of growth hormone deficiency in childhood and adolescence. Archives of Disease in Childhood 2016101 96-100. (https://doi.org/10.1136/archdischild-2014-307228)

4 Clemmons DR. Consensus statement on the standardization and evaluation of growth hormone and insulin-like growth factor assays. Clinical Chemistry 201157 555-559. (https://doi.org/10.1373/ clinchem.2010.150631) 
5 Schilbach K \& Bidlingmaier M. Laboratory investigations in the diagnosis and follow-up of GH-related disorders. Archives of Endocrinology and Metabolism 201963 618-629. (https://doi. org/10.20945/2359-3997000000192)

6 Kaplan SL, Abrams CAL, Bell JJ, Conte FA \& Grumbach MM. Serum growth hormone response to insulin-induced hypoglycemia in disorders of growth. Journal of Pediatrics 196567 956-959. (https:// doi.org/10.1016/S0022-3476(65)81883-2)

7 Frohman LA, Aceto T \& MacGillivray MH. Studies of growth hormone secretion in children: normal, hypopituitary and constitutionally delayed. Journal of Clinical Endocrinology and Metabolism 196727 1409-1417. (https://doi.org/10.1210/jcem-27-10-1409)

8 Raiti S, Davis WT \& Blizzard RM. A comparison of the effects of insulin hypoglicemia and arginine infusion on release of human growth hormone. Lancet 1967290 1182-1183. (https://doi. org/10.1016/S0140-6736(67)91896-X)

9 Root AW, Saenz-Rodriguez C, Bongiovanni AM \& Eberlein WR. The effect of arginine infusion on plasmagrowth hormone and insulin in children. Journal of Pediatrics 196974 187-197. (https://doi. org/10.1016/S0022-3476(69)80066-1)

10 Frasier SD. The serum growth-hormone response to hypoglycemia in dwarfism. Journal of Pediatrics 196771 625-638. (https://doi. org/10.1016/S0022-3476(67)80197-5)

11 GH Research Society. Consensus guidelines for the diagnosis and treatment of growth hormone $(\mathrm{GH})$ deficiency in childhood and adolescence: summary statement of the GH research society. Journal of Clinical Endocrinology and Metabolism 200085 3990-3993. (https:// doi.org/10.1210/jcem.85.11.6984)

12 Rosenfeld RG. Is growth hormone deficiency a viable diagnosis? Journal of Clinical Endocrinology and Metabolism 199782 349-351. (https://doi.org/10.1210/jcem.82.2.3841)

13 Guzzetti C, Ibba A, Pilia S, Beltrami N, Di Iorgi N, Rollo A, Fratangeli N, Radetti G, Zucchini S, Maghnie M, et al. Cut-off limits of the peak GH response to stimulation tests for the diagnosis of GH deficiency in children and adolescents: study in patients with organic GHD. European Journal of Endocrinology 2016175 41-47. (https://doi.org/10.1530/EJE-16-0105)

14 Federico G, Street ME, Maghnie M, Caruso-Nicoletti M, Loche S, Bertelloni S, Cianfarani S, Study Group on Physiopathology of growth processes \& Council of ISPED. Assessment of serum IGF-I concentrations in the diagnosis of isolated childhood-onset GH deficiency: a proposal of the Italian Society for Pediatric Endocrinology and Diabetes (SIEDP/ISPED). Journal of Endocrinological Investigation 200629 732-737. (https://doi.org/10.1007/BF03344184)

15 Blum WF, Alherbish A, Alsagheir A, El Awwa A, Kaplan W, Koledova E \& Savage MO. The growth hormone-insulin-like growth factor-I axis in the diagnosis and treatment of growth disorders. Endocrine Connections 20187 R212-R222. (https://doi.org/10.1530/ EC-18-0099)

16 Mavromati M, Kuhn E, Agostini H, Brailly-Tabard S, Massart C, Piketty ML, Arnoux A, Young J, Souberbielle JC \& Chanson P. Classification of patients with GH disorders may vary according to the IGF-I assay. Journal of Clinical Endocrinology and Metabolism 2017 102 2844-2852. (https://doi.org/10.1210/jc.2017-00202)

17 Shen Y, Zhang J, Zhao Y, Yan Y, Liu Y \& Cai J. Diagnostic value of serum IGF-1 and IGFBP-3 in growth hormone deficiency: a systematic review with meta-analysis. European Journal of Pediatrics 2015174 419-427. (https://doi.org/10.1007/s00431-014-2406-3)

18 Federico G \& Cianfarani S. Usefulness of serum insulin-like growth factor I assessment in the diagnosis of childhood-onset growth hormone deficiency. Hormone Research in Paediatrics 201074 145-148. (https://doi.org/10.1159/000314895)

19 Cianfarani S, Liguori A \& Germani D. IGF-I and IGFBP-3 assessment in the management of childhood onset growth hormone deficiency. In Endocrine Development, pp. 66-75. Eds S Cianfarani, DR Clemmons
\& MO Savage. Basel, Switzerland: Karger, 2005. (https://doi.org/ https://doi.org/10.1159/000085757)

20 Alawneh H, Khaledi O \& Maita J. Insulin like growth factor 1 as an indicator of growth hormone deficiency. Journal of the Royal Medical Services 201522 13-17. (https://doi.org/10.12816/0011355)

21 Haghshenas Z, Sotoudeh K, Karamifar H, Karamizadeh Z \& Amirhakimi G. The role of insulin like growth factor (IGF)-1 and IGF-binding protein-3 in diagnosis of growth hormone deficiency in short stature children. Indian Journal of Pediatrics 200976 699-703. (https://doi.org/10.1007/s12098-009-0115-0)

22 Cianfarani S, Liguori A, Boemi S, Maghnie M, Iughetti L, Wasniewska M, Street ME, Zucchini S, Aimaretti G \& Germani D. Inaccuracy of insulin-like growth factor (IGF) binding protein (IGFBP)-3 assessment in the diagnosis of growth hormone $(\mathrm{GH})$ deficiency from childhood to young adulthood: association to low GH dependency of IGF-II and presence of circulating IGFBP-3 18-kilodalton fragment. Journal of Clinical Endocrinology and Metabolism 200590 6028-6034. (https://doi.org/10.1210/jc.2005-0721)

23 Zweig MH \& Campbell G. Receiver-operating characteristic (ROC) plots: a fundamental evaluation tool in clinical medicine. Clinical Chemistry 199339 561-577. (https://doi.org/10.1093/ clinchem/39.4.561)

24 Elmlinger MW, Kühnel W, Weber MM \& Ranke MB. Reference ranges for two automated chemiluminescent assays for serum insulin-like growth factor I (IGF-I) and IGF-binding protein 3 (IGFBP-3). Clinical Chemistry and Laboratory Medicine 200442 654-664. (https://doi. org/10.1515/CCLM.2004.112)

25 Cacciari E, Milani S, Balsamo A, Spada E, Bona G, Cavallo L, Cerutti F, Gargantini L, Greggio N, Tonini G, et al. Italian crosssectional growth charts for height, weight and BMI ( 2 to $20 \mathrm{yr}$ ). Journal of Endocrinological Investigation 200629 581-593. (https://doi. org/10.1007/BF03344156)

26 Tanner JM \& Whitehouse RH. Clinical longitudinal standards for height, weight, height velocity, weight velocity, and stages of puberty. Archives of Disease in Childhood 197651 170-179. (https:// doi.org/10.1136/adc.51.3.170)

27 Moore DC, Ruvalcaba RHA, Smith EK \& Kelley VC. Plasma somatomedin-C as a screening test for growth hormone deficiency in children and adolescents. Hormone Research 198216 49-55. (https:// doi.org/10.1159/000179484)

28 Wang Y, Zhang H, Cao M, Kong L \& Ge X. Analysis of the value and correlation of IGF-1 with GH and IGFBP-3 in the diagnosis of dwarfism. Experimental and Therapeutic Medicine 201917 3689-3693. (https://doi.org/10.3892/etm.2019.7393)

29 Boquete HR, Sobrado PGV, Fideleff HL, Sequera AM, Giaccio AV, Suárez MG, Ruibal GF \& Miras M. Evaluation of diagnostic accuracy of insulin-like growth factor (IGF)-I and IGF-binding protein-3 in growth hormone-deficient children and adults using ROC plot analysis. Journal of Clinical Endocrinology and Metabolism $2003 \mathbf{8 8}$ 4702-4708. (https://doi.org/10.1210/jc.2003-030412)

30 Bussières L, Souberbielle JC, Pinto G, Adan L, Noel M \& Brauner R. The use of insulin-like growth factor 1 reference values for the diagnosis of growth hormone deficiency in prepubertal children. Clinical Endocrinology 200052 735-739. (https://doi.org/10.1046/ j.1365-2265.2000.00999.x)

31 Felício JS, Janaú LC, Moraes MA, Zahalan NA, de Souza Resende F, de Lemos MN, de Souza Neto NJK, Farias de Franco II, Leitão LTC, Silva LSD, et al. Diagnosis of idiopathic GHD in children based on response to rhGH treatment: the importance of GH provocative tests and IGF-1. Frontiers in Endocrinology 201910 638. (https://doi. org/10.3389/fendo.2019.00638)

32 Binder G, Huller E, Blumenstock G \& Schweizer R. Auxology-based cut-off values for biochemical testing of GH secretion in childhood. Growth Hormone and IGF Research 201121 212-218. (https://doi. org/10.1016/j.ghir.2011.05.007) https://ec.bioscientifica.com https://doi.org/10.1530/EC-20-0347 (c) 2020 The authors Published by Bioscientifica Ltd
This work is licensed under a Creative Commons Attribution-NonCommercial-NoDerivatives 4.0

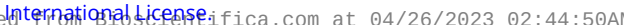


33 Bogazzi F, Manetti L, Lombardi M, Giovannetti C, Raffaelli V, Urbani C, Scattina I, Pepe P, Iannelli A, Martino E, et al. Impact of different cut-off limits of peak GH after GHRH-arginine stimulatory test, single IGF1 measurement, or their combination in identifying adult patients with GH deficiency. European Journal of Endocrinology 2011164 685-693. (https://doi.org/10.1530/EJE-10-1068)

34 Cianfarani S, Tondinelli T, Spadoni GL, Scire G, Boemi S \& Boscherini B. Height velocity and IGF-I assessment in the diagnosis of childhood onset GH insufficiency: do we still need a second GH stimulation test? Clinical Endocrinology 200257 161-167. (https:// doi.org/10.1046/j.1365-2265.2002.01591.x)

35 Grimberg A, DiVall SA, Polychronakos C, Allen DB, Cohen LE, Quintos JB, Rossi WC, Feudtner C, Murad MH \& Drug and Therapeutics Committee and Ethics Committee of the Pediatric Endocrine Society. Guidelines for growth hormone and insulinlike growth factor-I treatment in children and adolescents: growth hormone deficiency, idiopathic short stature, and primary insulinlike growth factor-I deficiency. Hormone Research in Paediatrics 2016 86 361-397. (https://doi.org/10.1159/000452150)

36 Inoue-Lima TH, Vasques GA, Scalco RC, Nakaguma M, Mendonca BB, Arnhold IJP \& Jorge AAL. IGF-1 assessed by pubertal status has the best positive predictive power for GH deficiency diagnosis in peripubertal children. Journal of Pediatric Endocrinology and Metabolism 201932 173-179. (https://doi.org/10.1515/jpem2018-0435)

37 Ali A, Hashim R, Khan FA, Sattar A, Ijaz A, Manzoor SM \& Younas M. Evaluation of insulin-like growth factor-1 and insulinlike growth factor binding protein-3 in diagnosis of growth hormone deficiency in short-stature children. Journal of Ayub Medical College, Abbottabad 200921 40-45.

38 Granada ML, Murillo J, Lucas A, Salinas I, Llopis MA, Castells I, Foz M \& Sanmarti A. Diagnostic efficiency of serum IGF-I, IGF-binding protein-3 (IGFBP-3), IGF-I/IGFBP-3 molar ratio and urinary GH measurements in the diagnosis of adult GH deficiency: importance of an appropriate reference population. European Journal of Endocrinology 2000142 243-253. (https://doi.org/10.1530/eje.0.1420243)

39 Binder G, Reinehr T, Ibáñez L, Thiele S, Linglart A, Woelfle J, Saenger P, Bettendorf M, Zachurzok A, Gohlke B, et al. GHD diagnostics in Europe and the US: an audit of national guidelines and practice. Hormone Research in Paediatrics 201992 150-156. (https:// doi.org/10.1159/000503783)

40 Blum WF, Böttcher C \& Wudy SA. Insulin-like growth factors and their binding proteins. In Diagnostics of Endocrine Function in Children and Adolescents, pp. 157-182. Eds MB Ranke \& PE Mullis. Basel, Switzerland: Karger, 2011. (https://doi.org/10.1159/000327407)

41 Loche S, Casini MR \& Faedda A. The GH/IGF-I axis in puberty. British Journal of Clinical Practice: Supplement 199685 1-4.

42 Mauras N, Rogol AD, Haymond MW \& Veldhuis JD. Sex steroids, growth hormone, insulin-like growth factor-1: neuroendocrine and metabolic regulation in puberty. Hormone Research 199645 74-80. (https://doi.org/10.1159/000184763)

43 Maghnie M, Strigazzi C, Tinelli C, Autelli M, Cisternino M, Loche S \& Severi F. Growth hormone (GH) deficiency (GHD) of childhood onset: reassessment of $\mathrm{GH}$ status and evaluation of the predictive criteria for permanent GHD in young adults. Journal of Clinical Endocrinology and Metabolism 199984 1324-1328. (https://doi. org/10.1210/jcem.84.4.5614)

44 Rosenfeld RG, Albertsson-Wikland K, Cassorla F, Frasier SD, Hasegawa Y, Hintz RL, Lafranchi S, Lippe B, Loriaux L \& Melmed S. Diagnostic controversy: the diagnosis of childhood growth hormone deficiency revisited. Journal of Clinical Endocrinology and Metabolism 199580 1532-1540. (https://doi.org/10.1210/jcem.80.5.7538145)

45 Trivin C, Souberbielle JC, Aubertin G, Lawson-Body E, Adan L \& Brauner R. Diagnosis of idiopathic growth hormone deficiency: contributions of data on the acid-labile subunit, insulin-like growth factor (IGF)-I and-II, and IGF binding protein-3. Journal of Pediatric Endocrinology and Metabolism 200619 481-489.

46 Patti G, Noli S, Capalbo D, Allegri AME, Napoli F, Cappa M, Ubertini GM, Gallizia A, Notarnicola S, Ibba A, et al. Accuracy and limitations of the growth hormone $(\mathrm{GH})$ releasing hormone-arginine retesting in young adults with childhood-onset GH deficiency. Frontiers in Endocrinology 201910 525. (https://doi.org/10.3389/ fendo.2019.00525)

47 Loche S, Bizzarri C, Maghnie M, Faedda A, Tzialla C, Autelli M, Casini MR \& Cappa M. Results of early reevaluation of growth hormone secretion in short children with apparent growth hormone deficiency. Journal of Pediatrics 2002140 445-449. (https://doi. org/10.1067/mpd.2002.122729)

Received in final form 9 October 2020

Accepted 22 October 2020

Accepted Manuscript published online 22 October 2020 https://ec.bioscientifica.com https://doi.org/10.1530/EC-20-0347 (c) 2020 The authors Published by Bioscientifica Ltd
This work is licensed under a Creative Commons Attribution-NonCommercial-NoDerivatives 4.0 International License.ifica com at $04 / 26 / 2023 \quad 02: 44: 50 \mathrm{Am}$ 